\title{
Investigating the effect of carbon dioxide on the acidity of the Ocean
}

\begin{abstract}
There is a significant effect of carbon dioxide on the acidification of the ocean. This research focuses on the acidification of the ocean and its effect on the animal life in the ocean. Also, it focuses on the effect of carbon dioxide concentration in the atmosphere on the ocean acidification. The data are collected from the research institutions and laboratories, such as National Snow and Ice Data Center (NSIDC), Japan, National Oceanic and Atmospheric Administration (NOAA), USA, Mauna Loa Observatory in Hawaii, and other sources of research about acidification of ocean. The results show that the acidity increases with increasing the amount of carbon dioxide in the atmosphere. This is because ocean absorbs nearly $50 \%$ of carbon dioxide from the atmosphere. Carbonate ions $\left(\mathrm{CO}_{3}{ }^{2-}\right)$ will be used in forming carbonic acid, which will increase the acidity of the water. Increasing the acidity of water will affect building of the animal Skeleton. It is recommended to reduce the amount of carbon dioxide in the atmosphere; therefore the acidity will be decreased in the ocean.
\end{abstract}

Keywords: Ocean acidification, Carbon dioxide, $\mathrm{pH}$ value, Ocean life, Environmental pollution
Volume 6 Issue 6 - 202I

\author{
AA El-Meligi ${ }^{1,2}$ \\ 'Physical Chemistry Department, National Research Centre, \\ Egypt \\ 2Math and Sci Department, College of Engineering, University of \\ Technology Bahrain, Bahrain \\ Correspondence: Professor Dr. Amin A El-Meligi, Physical \\ Chemistry Department, National Research Centre, Egypt, \\ Email ael_meligil0@hotmail.com
}

Received: October 12, 2021 | Published: November 18, 202 |

\section{Introduction}

Carbon dioxide is one of the green house gases. It is absorbed not only by atmosphere but also by the ocean. Approximately $50 \%$ of the emitted carbon dioxide goes into the ocean. As estimated, the emissions of carbon dioxide from fossil fuel combustion were 35.9 Gt in 2014. The emissions of fossil fuel were $0.6 \%$ above emissions in 2013 and 60\% above emissions in $1990 .{ }^{1}$ Effect of carbon dioxide on the global warming is well known. It transforms into carbonic acid in the ocean. The carbonic acid increases the acidity of the ocean by $26 \%$. The variation of the acidity has a significant effect on fishes and other organisms in the ocean. As known, acidity is expressed as a $\mathrm{pH}$ value, which is the hydrogen ion concentration, as shown in the equation $1 .^{2}$

$$
\mathrm{pH}=-\left[\log \left[\mathrm{H}^{+}\right]\right.
$$

The $\mathrm{pH}$ has a range from highly acidic solution $(\mathrm{pH}=0)$ to highly basic solution $(\mathrm{pH}=14)$ and neutral solution is the $\mathrm{pH}=7$. Lakes are healthy to accommodate organisms when the $\mathrm{pH}$ is 6 . There are a number of consequences due to increase of ocean acidity; if the $\mathrm{pH}$ is equal 5.5, many fishes will die, if $\mathrm{pH}$ is equal 5, a few fishes may be found and their reproduction will be affected. If the $\mathrm{pH}$ in the lake is 4.5 , the fishes will be sterile, for example, crayfish need calcium to form their external skeleton, as $\mathrm{pH}$ of the water decreases, the crayfish are unable to form new exoskeleton and they die. Reduced calcium also results in the malformed skeleton of some fishes. The acidity of the ocean has a significant effect on fishes and other organisms in the water. As estimated, global carbon emissions from fossil fuels are 9.795 giga tonne $(\mathrm{Gt})$, this amount of emitted carbon produces nearly $35.9 \mathrm{Gt}$ of global carbon dioxide emissions in $2014 .{ }^{1}$ Ocean, as one of the largest carbon absorbers in the planet, can absorb about one-third of all carbon emissions by human, this absorption reduces atmospheric carbon dioxide. ${ }^{3}$ As presented, the ocean can absorb about $50 \%$ of the emitted carbon dioxide. ${ }^{1}$ This amount lowers down the acidity of the water. In fact, the amount absorbed by the ocean is not fixed and there is a study confirms this finding ${ }^{4}$ As estimated, $\mathrm{pH}$ of ocean has drop by 0.1 unite since the industrial revolution; the $\mathrm{pH}$ value has dropped from 8.2 to 8.1 . This drop seems very low, but this drop is considerable because $\mathrm{pH}$ scale is logarithmic. There is a possibility that $\mathrm{pH}$ of ocean water may decrease about $120 \%$ by the end of 21 century, from 7.8 to 7.7, this depends on the amount of carbon dioxide add to the atmosphere with the current rate. This will create an ocean more acidic than any seen for the past 20 million years or more. ${ }^{5}$ Also, the ocean acidity is due to acid rains. The acid rains are formed because of the emission of gases from fossil fuel burning, such as, sulfur dioxide and nitrous oxide. Acid rain of sulfuric acid is formed due to reaction of sulfur dioxide reacts with water. Acid rain has a dangerous effect on water organisms. In fact, the $\mathrm{pH}$ of lakes should be 6 , this will help the organisms to survive in the water. If the $\mathrm{pH}$ is lower than 6 , this will be more dangerous on the organisms in the water. As $\mathrm{pH}$ of the water decreases, the crayfish are unable to form new exoskeleton and they die. Reduced calcium also results in the development of some fish with malformed skeleton. Acid rain can destroy the forests in many areas of the world. Acid rain also affects the aquatic ecosystems. High acidity of the lakes will lead to a loss of many types of organisms. ${ }^{6,7}$ It is estimated that the oceans have taken between a third and a half of carbon dioxide amount, which has been released by humans into the atmosphere since nearly 1850 . In fact, this huge amount of the carbon dioxide absorbed by the oceans has a great impact on the environment where the rate of climate change has been slowed down. The climate of the earth will be drastically affected if this huge amount of carbon dioxide is not absorbed by the oceans. On the hand, there is a negative impact of this huge amount of carbon dioxide on the acidity of the oceans, as estimated, the acidity of the oceans has increased by $26 \%$ since 1850 , the changing rate of acidity is nearly ten times faster than any other time in the last fifty five million years ago. Increasing of the ocean's acidity affects all organisms in the water, this will extend to impact the food chain, and the economic sources will be affected, such as fishing, tourism and aquaculture. ${ }^{8}$ As estimated, the current rate of acidity changes about 50 times faster than any time else. This is because nearly quarter of the carbon dioxide produced by human is absorbed in the oceans annually. In reality, over the past 250 years, there is about 560 billion tons of carbon dioxide absorbed by the ocean; this makes the acidity of surface water increases by $30 \% .^{9}$ Accordingly, acidity of the ocean has the attention of researchers over the past 5 years. Physical changes 
of the water during melting of the ice make the Arctic Ocean more sensitive to the changes of the acidity more than other areas of the ocean. ${ }^{10}$ This variation has a sound impact on the organisms in the water. The aim of the study focuses on the emitted carbon dioxide, which has absorbed by the ocean, and its effect on the acidity of the ocean.

\section{Research methodology}

The research methodology of the research will use the following tools:1-The recorded data about carbon dioxide and acidity of ocean will be collected from the recorded data by international research institutions and laboratories, such as National Oceanic and Atmospheric Administration (NOAA), USA, Mauna Loa Observatory in Hawaii, and any other source of data. The reports and researches about the atmospheric carbon dioxide and acidity of the ocean will be analyzed and interpreted.3. Statistical analysis will be conducted. The statistical methods will be selected depending on the data, such as descriptive analysis, correlation analysis.

\section{Results and discussion}

\section{Seawater $\mathrm{CO}_{2}$ and $\mathrm{pH}$ variation}

There is no doubt that the acidity of water has a great impact on the organisms. The main factor influences the level of acidity or the $\mathrm{pH}$ value of the water is the amount of carbon dioxide absorbed by the ocean. It is discussed that, over the past 250 years, there is about 560 billion tons of the carbon dioxide absorbed by the ocean, this makes the acidity of surface water increases by $30 \% .{ }^{9}$

As shown in Figure 1, there is a correlation between accumulation of carbon dioxide in the ocean and $\mathrm{pH}$ value of the water. The increase of the carbon dioxide amount in the ocean, the $\mathrm{pH}$ value will decrease..$^{11,12}$

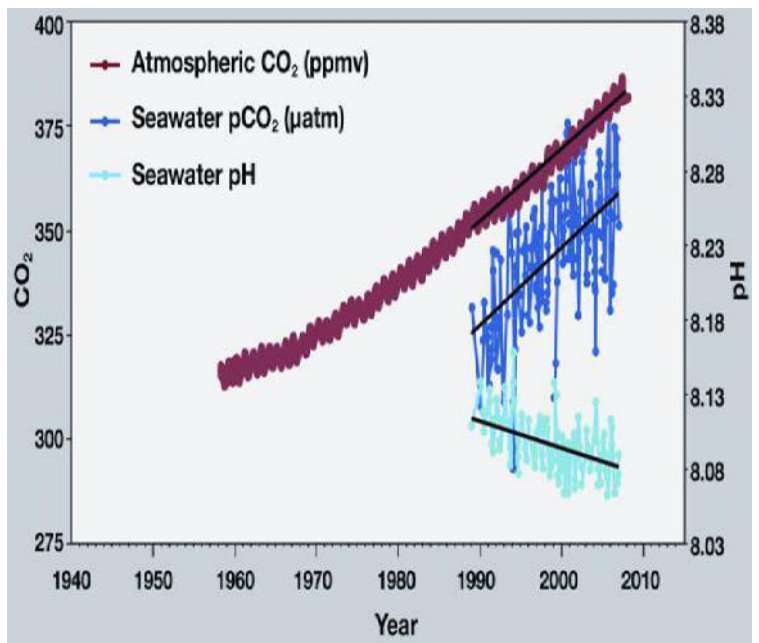

Figure I The relation between the level of $\mathrm{CO}_{2}$ in the atmosphere and its amount in the Ocean, and the effect on $\mathrm{pH}$ value of the ocean. ${ }^{10}$

As we can see in the Figure 1, there is a direct increase in the atmospheric carbon dioxide. This is due to emissions of fossil fuel burning of cars, factories and other activities. Accordingly, the amount of carbon dioxide in the seawater increases too, which leads to decrease the $\mathrm{pH}$ value of the seawater. This means that there will be a significant effect on the organisms in the water. Any change in the $\mathrm{pH}$ value, some fishes will be at risk. As has been discussed, if carbon dioxide adds to the atmosphere at current rates, $\mathrm{pH}$ of seawater may decrease $120 \%$ by the end of the 21 century.It will decreaseto 7.8 or 7.7 , and this will create high acidity of the ocean than anytime of the past 20 million years or more. ${ }^{13}$

\section{Acidity and marine life}

As discussed, the result of absorbing carbon dioxide by seawater is the formation of carbonic acid, as in the equation 2 .

$$
\mathrm{CO}_{2}+\mathrm{H}_{2} \mathrm{O} \rightarrow \mathrm{H}_{2} \mathrm{CO}_{3}
$$

Formation of the carbonic acid and quick change of marine chemistry will affect organisms' life and there will be no enough time to adapt. For example, more acidity of marine water leads to dissolving shells of some organisms. It is shown that the $\mathrm{pH}$ value of the marine water, especially oceans, has changed from 8.2 to 8.1, this is in the $19^{\text {th }}$ century. In fact, the change seems very small, but this change is considered the faster rate than at any time in the last three hundred million years. ${ }^{13}$ The change of oceans chemistry leads to unstable $\mathrm{pH}$ and need more time to be in its normal environment for organisms. Also, the $\mathrm{pH}$ scale is logarithmic, which means that any minimal change will be significant, for example, $\mathrm{pH} 4$ is 10 times more acidic than $\mathrm{pH}$ 5. It is 100 times more acidic than $\mathrm{pH}$ 6.If carbon dioxide has been continued to be added at current rates, the $\mathrm{pH}$ of the ocean may drop another $120 \%$ by the end of the current century, it means that the $\mathrm{pH}$ will drop to 7.8 or7.7. ${ }^{14}$ This change will make an ocean more acidic than any seen for the past 20 million years or more. In fact, some marine animals can survive with the variation of acidity, but others cannot survive. Some animals could survive during the last massive acidification time fifty five million years ago.

\section{Consequences of acidity}

As we have mentioned earlier, the increase of water acidity will affect the marine organisms, for example, as shown in the Figure 2, the image shows that shells can dissolve because of increasing the acidity of water and it will be hard for shell to grow.

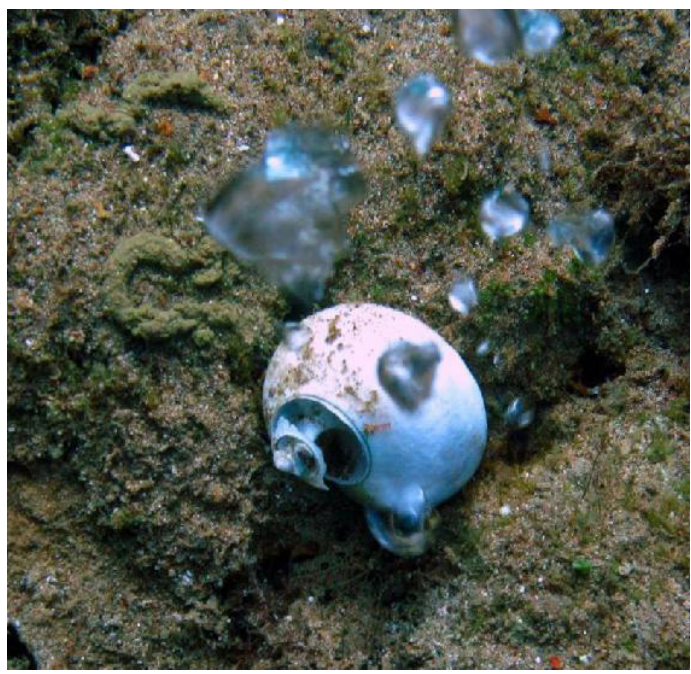

Figure 2 Effect of high acidity of water because of carbon dioxide on shells (Laetitia Plaisance).

In fact, there is a high sensitivity of many chemical reactions to any little change in $\mathrm{pH}$ value. For example, $\mathrm{pH}$ of human normal blood is between 7.35 and 7.45 , if the $\mathrm{pH}$ decreases from 0.2 to 0.3 , this can lead to different types of disease, such as comas, seizures and it may lead to death. Same things, any little change in the $\mathrm{pH}$ of the oceans can cause harmful effect on the life of marine animals, affecting chemical connections, growth, and reproduction process of organism. There is a chemical reaction occurs in presence of hydrogen ions, 
which affect the skeleton structure of the creatures in the oceans. ${ }^{14}$ This reaction is the combination of hydrogen ions with carbonations, as shown in equation 3 .

$$
2 \mathrm{H}^{+}+\mathrm{CO}_{3}^{2-} \longrightarrow \mathrm{H}_{2} \mathrm{CO}_{3}
$$

This reaction consumes the calcium ions in the water, which is used to produce calcium carbonate. This will affect the building of Skeleton of the marine creatures. ${ }^{14,15}$ Some animals can build their skeletons in the acidic media, but this needs more energy, and it can affect their reproduction process.

All in all, the future of ocean acidification will depend on the atmospheric amount of carbon dioxide. Stabilizing the amount of carbon dioxide in the atmosphere will neutralize the water and the $\mathrm{pH}$ will back to normal. It is stated that the atmospheric amount of carbon dioxide was much higher than the current level, but the acidity was under control. It means that the ocean was able to buffer and adapt. Currently, acidification is not very high, but the increase of carbon dioxide will increase it over time. Therefore, the emission of carbon dioxide must be controlled.

\section{Conclusion}

1) Burning of nonrenewable energy sources increase the amount of carbon dioxide in the atmosphere.

2) Oceans absorb about fifty percent of carbon dioxide emitted in the atmosphere.

3) Chemical reaction occurs in the water where hydrogen ion reacts with $\mathrm{CO}_{2}$ to form carbonic acid, which increases the acidity of the oceans.

4) Carbonate ions will be consumed because of high acidity. Hydrogen ions will react with carbonate ions.

5) Consumption of the carbonate ions will affect building the animals skeleton in the oceans.

6) Some animals in the ocean can adapt and survive in the presence of high acidity, but some animals cannot survive.

7) It is recommended that the solution to control the ocean acidity is to cut the emission of carbon dioxide in the atmosphere. This will not be happened unless renewable energy, such as solar energy, wind energy, hydrogen energy, hydroelectric energy, etc, replaces nonrenewable energy (oil, natural gas and coal).

8) We have to think out of the box to solve the problems of the earth. This can be done by making more research in this field.
9) Technology must play a role in solving the acidity problem of the ocean.

\section{Acknowledgments}

None.

\section{Funding}

None.

\section{Conflicts of interest}

All author listed here declare no conflict of interest exists.

\section{References}

1. https://www.co2.earth, 2018.

2. Timberlake KC. Chemistry: an introduction to general, organic, and biological chemistry. 12th edn. USA: Pearson Education Inc; 2015.

3. Jill Sakai, Climate change reducing ocean's carbon dioxide uptake. News, University of Wisconsin-Madison; 2011.

4. https://news.wisc.edu/climate-change-reducing-oceans-carbon-dioxideuptake/

5. https://ocean.si.edu/ocean-life/invertebrates/ocean-acidification

6. Enger ED, Smith BF. Environmental science: a study of interrelationships. 14th edn. McGraw-Hill Companies; 2016.

7. Cunningham WP, Cunningham MA. Environmental science: a global concern. 13th edn. McGraw-Hill Higher Education; 2015.

8. National climate change adaptation research facility. 2017.

9. La Shier B. Ocean acidification, warming waters endanger global fisheries, sea technology. 2018;59(1):41-42.

10. Cross, JN and Mathis, JT. Arctic ocean acidification bulletin of the American meteorological society. 2017;98(8):S145-S145.

11. Boyer, TP, Antonov, JI, Baranova, OK, et al. World Ocean database 2013. Sydney Levitus, Alexey Mishonov, Technical Ed.; NOAA Atlas NESDIS 2013.

12. National Oceanic and Atmospheric Administration (NOAA), USA, 2017.

13. Waters, H. Searching for the ocean acidification signal, Smithsonian Ocean. 2012.

14. Mackie McGraw, Hunter OA. An introduction to the chemistry of ocean acidification. 2011.

15. Marah Hardt, Carl Safina. Covering ocean acidification: chemistry and considerations. Yale Climate Connections. 2008. 